\title{
Can the millennium development goals catalyze development of a global freshwater regime?
}

\author{
Richard A. Meganck
}

Published online: 20 October 2010

(C) Springer Science+Business Media B.V. 2010

Some argue that freshwater should be considered as part of the 'global commons,' available to all based on some formula. Others resort to the water as a 'human right' argument. Still others support the case of privatization and costing all water use. I won't argue any of those points of view precisely, but rather that without some sort of shared understanding about freshwater access and use, we have virtually no chance to realize the Millennium Development Goals (MDGs) or for that matter almost any other global treaty or agreement dealing with the environment. In fact, I might go a bit further by stating that, as life doesn't exist without freshwater, what alternative do we have except to see water as a common thread in any discussion about investment or human progress?

For better or worse the progression of water from an isolated sectoral theme to its current position as a cross-cutting international economic development issue cannot be denied. The myriad of facts and figures regarding water are overwhelming: in excess of a billion people do not have access to sufficient quantities of clean drinking water, one third of the world's population currently experience severe water shortages, every eight seconds a child dies from a water-related disease, 68 percent of people in developing countries who consult a clinic are there because

R. A. Meganck ( $\square)$

International Water and Watersheds Center, Oregon

State University, Corvallis, OR, USA

e-mail: rameganck@gmail.com of a water-related problems, 30,000 people die each day from diseases related to water ${ }^{1}$-a total of 5 million each year and mostly from dehydration or diarrhea, rural African women spend 40 million hours. $^{2}$

Most recently as reported by the UNESCO Centre for Water Policy, Law and Science in Dundee, the Stockholm Statement to the High Level Plenary Meeting on the Millennium Development Goals (MDGs) noted that "the management and provision of water resources, water services and sanitation are some of the most cost efficient ways to address all the MDGs". This statement lists nine vital ways in which "continuing to neglect (water) is a recipe for disaster, and the failure of all MDGs" These are points were reinforced at the United Nations MDG Summit in New York (22nd-24th September 2010). ${ }^{3}$

But what do we do about it, now that such startling statistics have helped capture the world's attention? Is constructing an effective global water regime a realistic alternative? And why global, rather than

\footnotetext{
${ }^{1}$ United Nations 2007-2008 Human Development Report, UN Development Programme.

${ }^{2}$ Resolution adopted by the General Assembly: 62/136. Improvement of the situation of women in rural areas (A/ RES/62/136).

${ }^{3}$ Stockholm Water Week, 2010. The Stockholm Message from World Water Week to COP15.
} 
regional or local? Hoekstra and Chapagain (2008) ${ }^{4}$ argue that water itself has become a globalized resource requiring new mechanisms for interaction and policies. I suspect that it is high time that something is done. A simple web search for 'water governance organizations' produces 1.4 million references. Since the early 1970 s, there have quite literally been thousands of meetings to address the management and use of freshwater.

The debate and action surrounding the MDGs provides a unique opportunity under which to initiate formal talks about a global water management mechanism A governance regime by definition includes the formally and informally established institutional arrangement that study, finance, manage and administer a common property resource. Such an arrangement would include:

- Convention-A text negotiated by governments to include principles related to water resources and services and when ratified would bind its signatories to a given set of goals and responsibilities. This must be based on a shared sciencebased understanding of the issues relating to water and its management.

- Compact-A compact would include a set of voluntary actions negotiated by a select group of governments and civil society participants.

- Plan of Action (PoA)-An extended list of actions and responsibilities negotiated by governments through an intergovernmental process finalized at the ministerial level.

The entire process could start with a special meeting of the UN General Assembly (UNGA) with the technical support of the World Water Council (WWC) and facilitated by a special meeting at the next World Water Forum (WWF) in 2012. This is a very time consuming process requiring a government to propose a special session of the UNGA aimed at creating a secretariat that would organize the negotiation process among the Member States and name a lead UN agency to eventually house the convention secretariat. From my point of view UNESCO, WMO and FAO are the likely candidates to host a secretariat. The WWF becomes vital in organizing civil society interest (private, academic and NGO sectors) and input to the development of the Convention text and specifics of the Compact and PoA.

This three-tiered process while complex is unique in that the various components are not mutually exclusive. In the end, reaching an agreement on a binding international convention or compact is a worthy goal, but one that requires the dedication of many individuals and organizations for an extended period. Still the goal itself is worthy and although complex, it has come to dominate the international agenda precisely because there is no viable alternative.

Science has a vital role to play in this process and one that we should not shy away from. Indeed, science must be the catalyst for policy discussions. If in the end a solid agreement is reached, science will benefit as will future investment in its implementation.

In the interest of full disclosure, the author has worked in international organizations for 34 years and has co-authored a book on Global Environmental Governance. Neither of those two admissions, however, disqualify him from advocating development of some sort of global Accord, Protocol, Treaty, Compact, Plan of Action, Agreement, or Convention dealing with the management of freshwater. And 'yes' each of those terms has a distinct meaning in international parlance! The use and abuse of language in the international arena however is the subject for a separate opinion piece. ${ }^{4}$ Hoekstra, A. and Chapagain, A. K. (2008) Globalization of
Water, London, Blackwell Publishing. 